\title{
RESÚMENES DE TESIS
}

Pablo E. Ramírez Césped. "Ruperto Santa Cruz y los comienzos de la interpretación de la flauta moderna en Chile, 1856-1891: Recepción, instrumento, repertorio y publicaciones”. Barcelona: Universidad Autónoma de Barcelona, Facultad de Filosofía y Letras, Departamento de Historia del Arte y de Musicología, Doctorado en Programa de Historia del Arte y Musicología, febrero de 2021. Directores de tesis: Dr. César Calmell Piguillem; Dr. Alfonso Padilla Silva.

La tesis aborda la carrera artística del flautista, compositor, profesor y publicista chileno Ruperto Santa Cruz (1838-1906) entre 1856 y 1891, la que representa la primera experiencia profesional en el instrumento a nivel concertista que se dio en Chile y que, hasta ahora, no había sido estudiada. Se orienta principalmente hacia el significado de su trayectoria flautística, examinando la recepción de sus actuaciones por el territorio de la República, su instrumento -la flauta moderna, es decir, de sistema Boehm-, y su repertorio, primordialmente conformado por la paráfrasis operística de raíz belcantista italiana.

Además, el trabajo interroga acerca de sus obras, nueve de las que se tiene conocimiento, ediciones musicales, artículos y publicaciones. Estos trabajos están, en su mayor parte, comprendidos en el Álbum Musical Patriótico, periódico musical-literario que Santa Cruz editó entre 1880 y 1891 y del que se publicaron veinte números, y en el álbum Ecos Melódicos Americanos, publicado en 1890 y que tuvo tres entregas. Todas estas contribuciones, incluida su carrera como flautista, Santa Cruz las desplegó desde un vehemente carácter nacionalista, "patriótico" -por lo demás propio de su época-, pero que en conjunto configuran, en su caso, una experiencia musical de ribetes escasamente observados en un músico chileno durante esa centuria.

El escrito se estructura en una introducción, cinco capítulos y las conclusiones. En sus aspectos centrales, la Introducción presenta el trasfondo de la investigación, adscribiéndose a un marco teórico que plantea la relevancia del intérprete en la historia de la música. Asimismo, se formulan las preguntas que guiaron la pesquisa y la hipótesis respecto del significado de los aportes del músico. El primer capítulo, apoyado en fuentes impresas, actúa como un marco histórico que averigua acerca del arraigo de la práctica de la flauta en Chile durante la primera mitad del siglo. El segundo y tercer capítulo, documentados por fuentes hemerográficas, examinan el surgimiento y consolidación de la figura artística de Santa Cruz, desde su contacto con el virtuoso italiano Achille Malavasi en 1856 en Santiago hasta sus conciertos con Joseph White en 1878. El cuarto, con el auxilio de la amplia historiografía existente respecto de la flauta, analiza específicamente su instrumento y repertorio, elaborando a partir de estos, y de las influencias que recibió, una aproximación a su estilo interpretativo. El quinto capítulo expone e informa acerca del contexto y contenidos de sus publicaciones, artículos, pensamiento y obras. Por último, las conclusiones apuntan a que Ruperto Santa Cruz aportó a dar forma a la modernidad musical republicana a partir de un instrumento que, hasta entonces, no gozaba de categoría concertística en el país. La recuperación de su memoria es, por tanto, imprescindible para una comprensión más amplia de la historia de la música en Chile durante el siglo XIX.

Pablo Esteban Ramírez Césped

Universidad Autónoma de Barcelona ramirezcesped.pabloe@gmail.com 